Revue

Revue de l'histoire des religions

de Ihistoire des religions

$4 \mid 2012$

Varia

Saint Vincent FERRIER, Sermons, traduit du catalan par Patrick GIFREU et préfacé par Josianne CABANAS

Éditions de la Merci, Perpignan, 2010, 183 p., 18 cm, $20 €$, ISBN

978-2-9531917-5-2.

Sophie Delmas

(2) OpenEdition

Journals

Édition électronique

URL : http://journals.openedition.org/rhr/8003

DOI : $10.4000 /$ rhr.8003

ISSN : 2105-2573

Éditeur

Armand Colin

Édition imprimée

Date de publication : 1 décembre 2012

Pagination : $547-548$

ISBN : 978-2200-92796-7

ISSN : 0035-1423

Référence électronique

Sophie Delmas, « Saint Vincent fERRIER, Sermons, traduit du catalan par Patrick gifreu et préfacé par Josianne caBANAS », Revue de l'histoire des religions [En ligne], 4| 2012, mis en ligne le 24 janvier 2013, consulté le 22 septembre 2020. URL : http://journals.openedition.org/rhr/8003 ; DOI : https://doi.org/ $10.4000 /$ rhr.8003

Ce document a été généré automatiquement le 22 septembre 2020

Tous droits réservés 


\section{Saint Vincent FERRIER, Sermons, traduit du catalan par Patrick GIFREU et préfacé par Josianne CABANAS}

Éditions de la Merci, Perpignan, 2010, 183 p., $18 \mathrm{~cm}, 20 €$, ISBN

978-2-9531917-5-2.

\section{Sophie Delmas}

\section{RÉFÉRENCE}

Saint Vincent FERRIER, Sermons, traduit du catalan par Patrick GIFREU et préfacé par Josianne CABANAS, Éditions de la Merci, Perpignan, 2010, 183 p., 18 cm, $20 €$, ISBN 978-2-9531917-5-2.

1 Il est toujours agréable de voir paraître une édition ou une traduction de sermons médiévaux. Cet aspect de la civilisation médiévale, souvent encore méconnu, est alors accessible au plus grand nombre. C'est avec bonheur que l'on se plonge dans les sermons de Vincent Ferrier dont la traduction a été proposée à partir du catalan par l'écrivain Patrick Gifreu.

2 Contrairement à ce que le titre pourrait indiquer, il ne s'agit pas de la traduction intégrale des sermons du prédicateur dominicain, mais d'un choix de soixante-six extraits de sermons et de deux sermons complets. Premier regret : ni le traducteur, ni l'éditeur ne justifient le choix de ces différents textes. Ces derniers ont été « regroupés par thèmes et par ordre hiérarchique » (p.25), sans que l'on puisse avoir la moindre idée de cette hiérarchie. De même, ils ont été numérotés, mais sans que l'on sache à quoi correspond cette numérotation dans l'édition catalane originale utilisée ici, parue à Barcelone en 1993. Plus préoccupant du point de vue historique, ces textes ont été complètement détachés de leur contexte, si bien que le lecteur ignore même quelle fut l'occasion liturgique de ces sermons. De la même façon, le lecteur ignore où se situe l'extrait choisi à l'intérieur du sermon. Par exemple, le passage VI de cette édition 
commence ainsi : « le troisième office est l'office du cuisinier » (p. 36), mais le début du sermon n'a pas été retenu, si bien que le premier et le deuxième offices restent inconnus. De même, le passage XX débute par «La parole que nous avons prise pour thème signifie que l'œuvre des vertus... » (p. 91), mais le thème en question, c'est-à-dire le thème biblique qui est le fondement du sermon n'est pas donné.

Malgré tout, les extraits retenus, agréablement traduits, organisés autour de plusieurs grands thèmes (l'archétype de la prédication, deux sermons, la supériorité de la foi, l'au-delà...) sont d'un grand intérêt. À leur lecture, l'historien comprend la popularité de ce prédicateur que le talent autorisait au récit de nombreux exemples et petites histoires, telle celle des deux ermites (p.35) dans laquelle l'âme est comparée à un panier souillé de terre que le sermon permet de laver. On relève de rares coquilles («bâilleurs » d'un champ p. 123, « Mat 13, 339 » pour Mat 13, 39 p. 107).

Pour finir, l'ensemble de ces textes est précédé d'une introduction de la journaliste Josianne Cabanas dans laquelle sont présentées les grandes étapes de la vie de Vincent Ferrier, tout en insistant sur son lien avec Perpignan et sur ses œuvres (dont les titres sont donnés tantôt en français, tantôt en latin p. 11) : ses études à Valence, son rôle dans le schisme de 1378, son rôle auprès du pape Benoît XIII, sa décision de se consacrer à la prédication, le succès de ses sermons et les processions de flagellants qui les accompagnent. Là encore, le lecteur reste sur sa faim en raison de la totale absence de notes infrapaginales et de références bibliographiques. Il aurait au moins fallu citer les travaux de Bernard Montagnes, l'ouvrage ancien, mais encore valable de Mathieu Maxime-Gorce (Saint Vincent Ferrier (1350-1419), Paris, Plon, 1924) ou les récents articles que Franco Morenzoni a consacrés à la prédication de Vincent Ferrier ( « La prédication de Vincent Ferrier à Montpellier en décembre 1408 ", dans Archivum Fratrum praedicatorum, LXXIV, 2004, p. 225-271; Mirificus praedicator. Vincent Ferrier et la prédication mendiante, à l'occasion de son passage en Pays romand, éd. Bernard Hodel, Franco Morenzoni (Dissertationes Historicae, XXXII), Rome, 2006, 328 p.). On se prend à sursauter lorsqu'on lit qu'en 1285 «Philippe IV le Hardi » (pour Philippe III le Hardi) meurt à Perpignan (p. 17).

Les jeunes éditions de la Merci (nées en 2008) ont pour ambition de traduire en français de grands textes catalans, en présentant, dans les préfaces, les dernières avancées de la recherche internationale. Cette ambition est louable, et souhaitons que ces quelques remarques puissent contribuer à leur effort.

\title{
AUTEURS
}

\author{
SOPHIE DELMAS
}

UMR 5648, Université Lyon 2. 